\title{
Segurança do teste de inclinação no diagnóstico de síncope reflexa
}

\author{
Suzigan, B.H.; Barbisan, J.N.; Sant'anna, P.S.; Pedroso, V.B.; Dossin, I.A.; \\ Apresentador: Bruna Helena Suzigan
}

\section{Resumo}

Introdução: O teste de inclinação (TI) tem se mostrado seguro em diferentes amostras e não há relato de nenhuma morte durante sua realização. Diversas complicações já foram relatadas, como infarto agudo do miocárdio, arritmias ventriculares e assistolia prolongada. Devido aos poucos relatos na literatura e a sua crescente demanda para a investigação de síncope, há necessidade de estudos maiores sobre a segurança do TI. Objetivo: avaliar a segurança do TI através da frequência de complicações em uma instituição de referência em cardiologia. Métodos: estudo retrospectivo transversal, de 2001 e junho de 2012 no Instituto de Cardiologia do Rio Grande do Sul. Buscou-se na descrição dos exames a presença de sintomas e alterações no eletrocardiograma considerados inesperados. Protocolos do TI: Todos os pacientes ficaram em posição supina por 20 min. Depois eram inclinados a $70^{\circ}$ e mantinham-se assim por mais 46 minutos (fase passiva). Esta fase era seguida de infusão de isoproterenol 1-4 microgramas/min objetivando elevar a frequência cardíaca em pelo menos $25 \%$ (fase ativa, com duração de 20 min). Posteriormente, houve alteração no protocolo: a fase passiva passou para 20 minutos e a administração de nitroglicerina sublingual $400 \mu \mathrm{g}$ passou a ser uma alternativa ao para o isoproterenol. Nos pacientes que se recusaram a utilizar as medicações, o protocolo previu apenas fase passiva por $46 \mathrm{~min}$. O TI foi considerado positivo quando houve síncope ou pré- síncope. Resultados: Foram revisados 1712 exames de 1654 pacientes. Houve predomínio mulheres $(60,8 \%)$. A média de idade entre as mulheres foi 41,5 anos (6 a 90 anos) e de 47,6 (6 a 93 anos) entre os homens. Foram encontradas 10 complicações: dor torácica sugestiva de angina (5) taquicardia sinusal (1), extra-sístoles ventriculares e infradesnivelamento do segmento ST acompanhados de dor torácica (1) síncope com convulsão, acompanhada de bloqueio A-V total sem ritmo de escape ventricular (1) distúrbio de condução A-V tipo Mobitz I (1) hipotensão arterial e bradicardia (1) e crise de ansiedade (1). Conclusão: o TI mostrou-se seguro em nosso meio, com uma taxa de complicações de apenas $0,5 \%$, considerando todas como decorrentes do TI. Angina foi a complicação mais frequente.

\section{Referência:}

Suzigan, B.H.; Barbisan, J.N.; Sant'anna, P.S.; Pedroso, V.B.; Dossin, I.A.;. Segurança do teste de inclinação no diagnóstico de síncope reflexa. In: Il Congresso Brasileiro de Medicina Hospitalar - II CBMH [= Blucher Medical Proceedings, vol.1, num.5] São Paulo: Editora Blucher, 2014. p.99

DOI 10.5151/medpro-II-cbmh-099 